\title{
Patient preferences and satisfaction in a multispecialty infusion center
}

\author{
This article was published in the following Dove Press journal: \\ Patient Preference and Adherence \\ 19 May 2014 \\ Number of times this article has been viewed
}

\author{
Barbara E Ostrov' \\ Kristine Reynolds ${ }^{2}$ \\ Lisabeth V Scalzi' \\ 'Departments of Pediatrics and \\ Medicine, ${ }^{2}$ Department of Nursing, \\ Penn State Hershey Medical Center, \\ Hershey, PA, USA
}

\begin{abstract}
Purpose: Direct feedback from patients about their preferred modes of medication administration has been increasingly sought by providers to develop care programs that best match patient goals. Multispecialty infusion centers generally provide care to hematology-oncology (HO) and non-HO patients in one unit, with the same nursing staff. Our staff perceived that this was dissatisfying to our non-HO patients. We assessed patient satisfaction, as well as nursing and physician perceptions of patient preference/satisfaction with our infusion center, to determine whether a separate unit should be recommended when designing our new Cancer Institute Infusion Center.
\end{abstract}

Patients and methods: A seven-question Likert scale satisfaction survey for patients, and a separate survey to assess nurses' and physicians' perception of patient satisfaction, were developed. The survey was administered to non-HO patients receiving infusions, doctors prescribing infusions, and nurses administering infusions. Results of the survey were compared between groups to assess differences in responses.

Results: Responses were received from 52 non-HO patients, 18 physicians, and 13 nurses. Patients had more satisfaction, on all survey items, with the multispecialty infusion center than had been realized by physicians and nurses. Analysis demonstrated that patients were satisfied with care in a multispecialty infusion unit and were in favor of continuing their care in this combined center. Total scores of patient surveys were significantly different $(P<0.001)$ from those of physicians and nurses, who had assumed patients would prefer to have their care in a non-HO infusion setting.

Conclusion: Understanding patient preferences is an important step in deciding the structure of infusion centers. Based on these survey conclusions, a combined multispecialty infusion center has been continued at our institution, thus improving quality by including patients in decision-making affecting their care.

Keywords: patient care, infusion preferences, non-oncology patients, infusion therapy

\section{Introduction}

Identifying and adhering to patient preferences positively influences satisfaction with health care delivery and also leads to a perceived higher quality of care. Direct feedback from patients about preferred modes of medication administration has been sought increasingly by providers to develop care programs that best match patient goals. ${ }^{1}$ Given this information, it is surprising that some health care providers continue to direct medication selections, and that health care administrators still implement policy decisions while assuming patient preferences, without actually questioning the patients. ${ }^{2,3}$

Multispecialty infusion centers generally provide care to hematology-oncology (HO) and non-HO patients in one unit, with the same nursing staff. The knowledge gap and lower comfort level of some infusion center nurses in managing non-oncologic 
diseases $^{4}$ is exemplified by anecdotal reports concerning several patients of one of the authors, cared for in our combined (but mainly HO) infusion center. Postmenopausal osteoporosis patients were educated about the antimetastatic effects of intravenous bisphosphonates. The benefits of rituximab in lymphoma management were explained to patients with non-HO disease. Following these discussions, some non-HO patients were concerned they might have malignant diseases of which they were unaware. Issues concerning disease-specific nursing expertise suggested to some of our physicians and nurses that non-HO patients could be better served in an infusion center dedicated to this population. Additionally, while it has been postulated that patients with rheumatic and other non-HO diseases might have personal reservations about being treated in a multidisciplinary infusion center (together with HO patients), ${ }^{3}$ there are no published reports that assess this common scenario by surveying these patients.

As a result of these conflicting impressions, in 2009, when our new Cancer Institute Infusion Center was being designed, we considered developing a separate infusion unit for our non-HO population. We first assessed patient satisfaction with our multispecialty infusion center, as well as nursing and physician perceptions of patient preference/ satisfaction, to determine whether a separate unit should be recommended.

\section{Material and methods}

In 2009, the infusion center at Penn State Hershey Medical Center was comprised of 18 primarily open infusion bays, with 14 infusion therapy nurses, who cared for all the patients. Penn State Hershey Medical Center is an academic tertiary/ quaternary care medical center in Central Pennsylvania with about 800 primary care and specialist physicians, providing over 900,000 outpatient visits per year. During 2008-2009, a total of 13,231 infusions were performed; 11,247 (85\%) were HO patients and 1,984 (15\%) were non-HO patients. The quantity and type of non-HO infusions and subspecialty prescribing services are summarized in Table 1.

A seven-question Likert scale satisfaction survey for patients and a separate survey for nurses and physicians were developed with infusion center nursing leadership (Supplementary materials). Each question item could be rated from 1 to 5 , with 5 being the best score (for a maximum score of 35). We focused the questions on satisfaction with the multispecialty structure of our center and considerations for future modifications. The tool was designed to assess differences in patient satisfaction and staff perception of patient satisfaction with the care provided by our multispecialty infusion unit team. Surveys were collected over 2 weeks from three groups of individuals: non-HO patients, center nurses providing infusions, and ordering physicians. Patients were given the opportunity to comment on the infusion center at the end of the survey. No staff or patient identifiers were collected with the survey materials.

\section{Statistical analysis}

Reliability of the tool was measured using Cronbach's alpha. Mean sums for all patient, physician, and nurse responses were calculated and analyzed using one-way ANOVA. A post hoc analysis was examined to determine which groups were similar. Means of responses for each question were analyzed between all groups using one-way ANOVA, and a post hoc analysis was used to examine intergroup differences. Statistical analysis was performed using JMP version 10 software (SAS Institute, Cary, NC, USA).

\section{Results}

Surveys were completed by 13 of the infusion center nurses (93\% response rate), 52 of the approximately 78 non-HO patients (67\% response rate), and 18 of the 39 ordering physicians (46\% response rate). The most frequent patient diagnoses for the non-HO patients included: systemic lupus erythematosus (SLE), rheumatoid arthritis (RA), inflammatory bowel disease (IBD), psoriasis, osteoporosis, and immunodeficiency. The majority of the ordering services included rheumatology, dermatology, gastroenterology, immunology, and neurology (see Table 1). The satisfaction survey tool was highly reliable, with Cronbach's alpha equal to 0.92 .

Table I Non-HO infusions and subspecialty prescribing services

\begin{tabular}{lll}
\hline & & $\#(\%)$ \\
\hline Medical service & Rheumatology & $912(46 \%)$ \\
& Gastroenterology & $268(14 \%)$ \\
& Dermatology & $130(7 \%)$ \\
& Allergy-Immunology & $102(5 \%)$ \\
& Neurology & $88(4 \%)$ \\
Medication & Others & $484(24 \%)$ \\
& & \\
& Infliximab & $794(40 \%)$ \\
& Intravenous immunoglobulin & $359(18 \%)$ \\
& Methylprednisolone & $298(15 \%)$ \\
& Abatacept & $177(9 \%)$ \\
& Rituximab & $80(4 \%)$ \\
& Zolendronic acid & $48(2 \%)$ \\
& Cyclophosphamide & $45(2 \%)$ \\
& Other & $183(9 \%)$ \\
\hline
\end{tabular}

Abbreviation: $\mathrm{HO}$, hematology-oncology. 
Table 2 Survey and results

\begin{tabular}{|c|c|c|c|c|c|}
\hline \multicolumn{2}{|c|}{$\begin{array}{l}\text { Scale 4-5: Agree, Strongly agree } \\
\text { 3: Neutral I-2: Strongly disagree, Disagree }\end{array}$} & \multirow{2}{*}{$\begin{array}{l}\text { Patient response } \\
\text { average }(\mathbf{N}=\mathbf{5 2}) \\
4.52 \pm 0.85\end{array}$} & \multirow{2}{*}{$\begin{array}{l}\text { Physician response } \\
\text { average }(\mathbf{N}=18) \\
3.50 \pm 0.97\end{array}$} & \multirow{2}{*}{$\begin{array}{l}\text { Nurse response } \\
\text { average }(\mathbf{N}=13) \\
3.77 \pm 1.24\end{array}$} & \multirow{2}{*}{$\frac{P \text {-value }}{0.0004}$} \\
\hline I. & $\begin{array}{l}\text { I am/My patient is content having infusions } \\
\text { in a cancer infusion center. }\end{array}$ & & & & \\
\hline 2. & $\begin{array}{l}\text { I am/My patient is not bothered by the } \\
\text { cancer-focused environment. }\end{array}$ & $4.31 \pm 1.15$ & $3.31 \pm 0.95$ & $3.62 \pm 1.26$ & 0.005 \\
\hline 3. & $\begin{array}{l}\text { I understand/My patient understands that their } \\
\text { disease is not a form of cancer. }\end{array}$ & $4.76 \pm 0.59$ & $4.17 \pm 0.92$ & $3.92 \pm 1.26$ & 0.0009 \\
\hline 4. & $\begin{array}{l}\text { It will not bother me/my patient to enter the } \\
\text { Cancer Institute. }\end{array}$ & $4.40 \pm 1.09$ & $3.06 \pm 1.03$ & $3.38 \pm 1.32$ & $<0.0001$ \\
\hline 5. & $\begin{array}{l}\text { I have/My patient has no preference for a } \\
\text { non-cancer infusion center. }\end{array}$ & $4.24 \pm 1.09$ & $2.50 \pm 0.89$ & $3.00 \pm 1.54$ & $<0.0001$ \\
\hline 6. & I am/My patient is not worried about their privacy. & $4.33 \pm 1.10$ & $2.81 \pm 0.91$ & $2.50 \pm 1.09$ & $<0.0001$ \\
\hline 7. & $\begin{array}{l}\text { It will be no problem for me/my patient to move } \\
\text { their infusion unit in the future if more space } \\
\text { is needed for } \mathrm{HO} \text { patients. }\end{array}$ & $4.02 \pm 1.29$ & $2.63 \pm 1.31$ & $2.75 \pm 1.22$ & 0.0001 \\
\hline
\end{tabular}

Abbreviation: $\mathrm{HO}$, hematology-oncology.

Mean response scores from the three groups (patients, nurses, and physicians) are reported in Table 2, with ANOVA results for differences between the three means. Uniformly, patients expressed high satisfaction with their care at the infusion center. Their responses to the survey indicated no hesitation about being cared for in a primarily oncology unit. Non-HO patients who completed the survey understood that their inflammatory disease was not a manifestation of cancer ( $4.76 \pm 0.59$ out of 5$)$ and they expressed no dissatisfaction about sharing the unit with $\mathrm{HO}$ patients $(4.52 \pm 0.85)$. Surveyed individuals also did not report a desire to have a separate non-HO infusion unit (4.24 \pm 1.09$)$. Additionally, they were not concerned about privacy issues related to the open infusion bays in the infusion center ( $4.3 \pm 1.0)$, nor were they concerned with the idea of potentially moving their infusion space again in the future, if needed (4.02 \pm 1.29$)$. In contrast to these patient responses to the survey, the non-HO physicians and infusion center nurses reported lower perceived patient satisfaction on all these measures. Patients had greater satisfaction on all items than had been realized by the physicians as well as the nurses.

The sum of the mean scores for the patient survey questions was $30.33 \pm 7.40$, versus $20.17 \pm 8.46$ for the physicians, and $22.54 \pm 8.50$ for the nurses. The patient and nurse, as well as the patient and physician, results were significantly different from one another $(P<0.0001)$. Post hoc analysis demonstrated that patient responses were significantly different from nurses $(P=0.002)$ and doctors $(P<0.001)$. Interestingly, nurses' and doctors' responses were no different from each other $(P=0.45)$ (Figure 1).

There were significant differences between all three groups for each individual question (see Table 2). In the post hoc analysis, patient responses were significantly different from physician responses for every question (Table 3 ). Responses between patients and nurses were significantly different for all questions, except for Question 2, which addressed patient concern about being in a "cancer-focused environment" $(P=0.06)$. Nurses were in closer agreement with patients than were physicians, such that nurses understood that patients were not bothered by the oncology emphasis of the center. There was not a significant difference between nurses and patients, for this question. There were no significant differences in responses between nurses or physicians for any of the questions.

In their comments, the non-HO patients reported high satisfaction with their nursing care, and desired to continue to have their infusions administered by these experienced

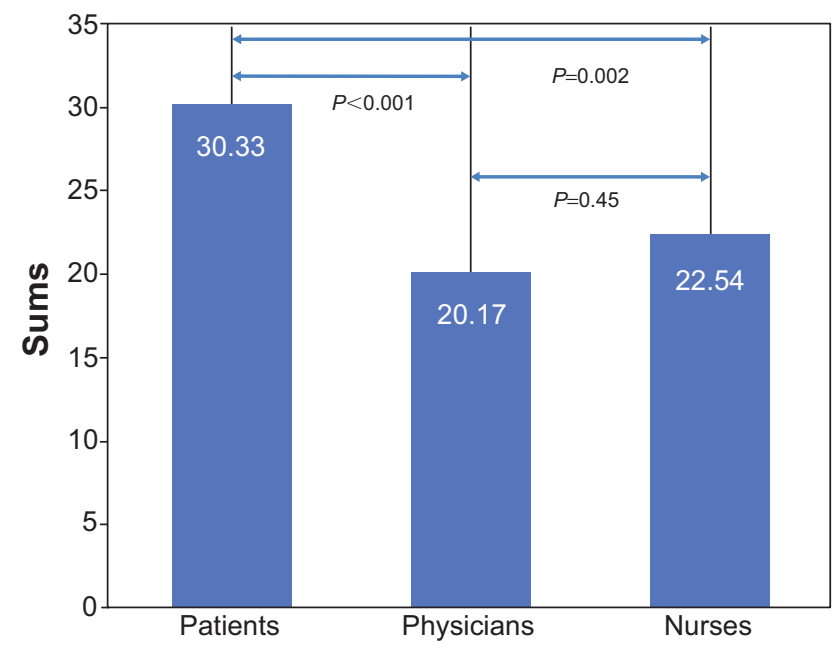

Figure I Mean infusion room satisfaction scores of patients, nurses, and physician providers. 
Table $3 P$-values for intergroup mean responses to individual survey questions

\begin{tabular}{llll}
\hline & Patient versus physician & Patient versus nurse & Physician versus nurse \\
\hline Question I & 0.0001 & 0.01 & 0.52 \\
Question 2 & 0.002 & 0.06 & 0.47 \\
Question 3 & 0.002 & 0.0007 & 0.54 \\
Question 4 & $<0.0001$ & 0.005 & 0.55 \\
Question 5 & $<0.0001$ & 0.0006 & 0.20 \\
Question 6 & $<0.0001$ & $<0.0001$ & 0.42 \\
Question 7 & 0.0004 & 0.003 & 0.80 \\
\hline
\end{tabular}

and dedicated nurses. Patients lauded the nurses in their roles also caring for the $\mathrm{HO}$ patient population. Those surveyed also reported that sharing the unit with cancer patients gave them a better perspective on their own disease and made them more empathetic to the oncology patients.

\section{Discussion}

Surprisingly, unlike prior assumptions reported by physicians and administrators, ${ }^{2,3}$ as well as our own original assumptions, non-HO patients were highly satisfied with infusion therapy at a primarily $\mathrm{HO}$ (but multidisciplinary) infusion unit. Our non-HO patients were content with the infusion space and with sharing care alongside $\mathrm{HO}$ patients, as provided by the infusion nurses. The most important issue for these individuals was not the environment but the high quality, skilled nurses who administered their infusion medications. Similar comments were made by Australian RA patients surveyed about the benefits of a unique community-based infusion program. Treatment and reassurance by a trained nurse in a medical setting was the primary benefit cited concerning the infusion center. ${ }^{5}$

Satisfaction with treatment increases when patient preferences guide selection of therapy. ${ }^{6-8}$ High risk immunomodulatory biologic medications are selected by patients to optimally manage their complex inflammatory diseases, including IBD, RA, psoriatic arthritis, and SLE. Most current biologic therapy options are either self-injected or given as an intravenous infusion, often administered in outpatient infusion centers. ${ }^{5,9}$ The variety of agents available and the numbers of non-HO patients being prescribed these medications worldwide are increasing rapidly. In US claims data reports, $13 \%$ of infusions are given for rheumatologic diagnoses: ${ }^{9}$ a number similar to the total non-HO infusions in our infusion center (15\%). Claims trend reports also identify infliximab (used for several disorders, including RA, psoriasis, and IBD) as the most commonly infused non-HO biologic agent, consistent with our infusion center's usage (Table 1). Infliximab is also the single largest infusion expenditure of all infused agents. ${ }^{9}$ Therefore, a large impact may be achieved by engaging patients in decision making surrounding their choice of infused versus non-infused biologic agents. Patient preferences regarding perceived risks and benefits of treatment, as well as method of administration (oral, injected, intravenous) and location of therapy (home, medical office, hospital center) are crucial in developing successful treatment plans. ${ }^{7,8,10,11}$ In previous reports, some patients, when asked, prefer intravenous therapies over other parenterally administered options. ${ }^{2,5,6,8}$ In one study, ${ }^{2}$ in contrast to physician assumptions, many German RA patients preferred infusion therapy. Two-thirds of these patients preferred an infusion every 6-9 months; only $12.9 \%$ of patients preferred self-injections every second week, but only $2 \%$ preferred a monthly infusion. The majority of rheumatologists (94\%) had assumed that their patients, given the choice, would prefer self-injection rather than intravenous therapies infused at the hospital or unit - in contrast to the actual patient preferences. ${ }^{2}$ In another study, Danish RA patients preferred their current biologic regimen of either intravenous infusion or subcutaneous injection. However, $87 \%$ of health care providers assumed the patients would prefer self-injection. ${ }^{10}$ In Swiss IBD patients, more patients (approximately 65\%) preferred self-injection of biologic agents. Ease of use and the time required for infusion therapy are key factors influencing these patients' choices of modality for medication. ${ }^{8,10}$ These studies emphasize that patients' individual preferences should be taken into account when prescribing immunomodulatory drugs. Our study addressed patient preferences regarding infusion center location and patient mix rather than preference for type of biologic medication prescribed. However we clearly demonstrated that, like these other studies, providers' prediction of patient preferences may not be accurate. Hence, caregivers should not be directive in selecting patient therapy.

Patients often express dissatisfaction with health care due to concerns about access to care and the time spent with providers. These issues may be improved when utilizing 
infusion centers with medical and nursing teams aligned. ${ }^{1,11}$ Infusion centers are often closer to home (improved access to care) and offer one-on-one time with nurses, and sometimes also with physicians (more time spent with health care providers). ${ }^{1,8,12}$ Additionally, infusion center nurses provide direct patient care, such as placement of intravenous lines, laboratory blood draw, administration of medication, and assessment of vital signs and medication tolerance. ${ }^{11,13}$ Infusion nurses also educate patients about their diagnoses, the role of the medications being infused, and potential side effects they need to be aware of. ${ }^{11,13}$ As noted above, many infusion center nurses care mainly for patients with $\mathrm{HO}$ diseases. Nursing staff at such centers may have limited experience of caring for patients with rheumatic and other inflammatory diseases, even though these groups of patients may comprise the second largest population under their care. ${ }^{4}$ The case examples cited in the introduction exemplify these difficulties.

Given financial and space considerations, multispecialty infusion centers are likely to continue to be commonplace in most communities. ${ }^{3}$ Almost $40 \%$ of infusions are performed at hospital-based centers, likely similar to ours. ${ }^{12}$ Additionally, for some US patients, their insurance carriers preferentially reimburse hospital-based infusion therapy over at-home self-injection, encouraging such individuals to have their biologic therapy administered at infusion centers. ${ }^{9}$ Considering these realities, in light of the preponderance of infusion nurses' HO patient experience, yet with a significant proportion of patients with non-HO diagnoses under their care, understanding the differing clinical and educational needs of non-HO patients may be an important educational gap to close for these health care professionals. ${ }^{4,13}$

Strengths of this study include that the results may be directly applicable to other infusion centers that are considering whether to have separate or unified infusion centers for $\mathrm{HO}$ and non-HO patients. Potential weaknesses of this study include the overall numbers of participants involved; we were limited to the number of providers, nurses, and non-HO patients available to answer the survey. In addition, this survey was conducted while nurses and patients were actively engaged in the project design of the new Cancer Institute Infusion Center. If the survey had occurred prior to these conversations, it is possible that the responses could have differed. Also, we did not collect demographic information from our study subjects. It is possible that certain patient groups may have differing responses to survey questions. It is unknown whether there are cultural or geographic differences in perceptions by non-HO patients regarding care at multispecialty centers. It is notable that the limited published literature demonstrating patient preference for types and/or location of biologic therapies is derived from work with varied populations. ${ }^{1,2,5,8,11,12}$

As providers, we may be directive in our care and may make assumptions about our patients' preferences. ${ }^{2}$ In an era focusing on improving value, we need to be mindful of quality as well as cost, using the following definition: value $=$ quality $/$ cost. ${ }^{14}$ Quality includes patient safety, patient satisfaction, and patient experience, the latter two of which can be improved by including patients in decisions affecting their care. Having one multispecialty infusion center likely decreased our center's overall costs by avoiding creating more than one infusion area, hiring more nurses to staff two centers, and dividing ancillary services. By simply assessing patients' opinions, we embraced the opportunity to continue high-quality multispecialty care, as perceived by our patients. We benefited by avoidance of cost that would have been incurred when building two infusion units; ultimately, we maintained value for the patient. Our report demonstrates that medical institutions have the potential to reduce redundant staffing, as well as physical space, by involving patients in planning optimal care delivery systems.

In summary, our physicians and nurses were significantly more concerned than were the non-HO patients about their therapy in the multispecialty (but primarily oncology) infusion center. Improved understanding of patient preferences was clearly demonstrated to providers and nurses by this survey. Based on these survey conclusions, a combined multispecialty infusion center is acceptable to patients and has been continued at our institution. We believe that this is the first publication to address the issue of patient preferences regarding a multispecialty infusion center. Hence, further research on this subject is needed, to better understand optimal treatment paradigms for the large, non-HO infusion population. Future tools need to include assessment of the current opinion of our non-HO patients in their new combined infusion center. New surveys should also include demographic information, and individuals from diverse backgrounds, to assess the potential impact of cultural differences on patient preferences, as well as the relationships of diverse non-HO patients with their health care providers. Pediatric infusion patients and their parents may have unique concerns, and their opinions should also be sought, as we strive to maximize patient- and family-centered care - the cornerstone of patient preference-focused health care. 


\section{Author contributions}

All three authors, B Ostrov, K Reynolds, and L Scalzi, made substantial contributions to conception and design, acquisition of data, analysis and interpretation of data; contributed to drafting and revising the article; gave final approval of the version to be published; and all are in agreement to be accountable for all aspects of the work in ensuring that questions related to the accuracy or integrity of any part of the work are appropriately investigated and resolved.

\section{Acknowledgments}

We thank Michael J Beck, MD for his editorial contribution and Alan Brechbill for his original suggestion to perform this project.

\section{Disclosure}

The authors report no conflicts of interest in this work.

\section{References}

1. Kjeken I, Dagfinrud H, Mowinckel P, Uhlig T, Kvien TK, Finset A. Rheumatology care: involvement in medical decisions, received information, satisfaction with care, and unmet health care needs in patients with rheumatoid arthritis and ankylosing spondylitis. Arthritis Rheum. 2006;55(3):394-401.

2. Willeke P, Becker H, Wassenberg S, Pavenstadt H, Jacobi AM. Bewertung einer Infusionbehandlung der rheumatoiden Arthritis durch Patienten und Rheumatologen [Patient/rheumatologist evaluation of infusion treatment for rheumatoid arthritis]. Z Rheumatol. 2011;70(3):232-234, 236-238. German.

3. Baker JJ, Leovic TM, O'Connor CA, Pierce CA. Relocating rheumatology patients to a new infusion center at Duke: a case study. Health Care Manag (Frederick). 2003;22(2):159-169.
4. Furfaro N, Mease PJ. Nursing considerations for infusion therapy in rheumatoid arthritis versus malignancy. J Infus Nurs. 2008;31(6): 350-360.

5. Voight L. Survey of a community-based infusion program for Australian patients with rheumatoid arthritis requiring treatment with tocilizumab: patient characteristics and drivers of patient satisfaction and patient-perceived benefits and concerns. Patient Prefer Adherence. 2012;6:275-283.

6. Barton JL. Patient preferences and satisfaction in the treatment of rheumatoid arthritis with biologic therapy. Patient Prefer Adherence. 2009;3:335-344.

7. Bewtra M, Johnson FR. Assessing patient preferences for treatment options and process of care in inflammatory bowel disease: a critical review of quantitative data. Patient. 2013;6(4):241-255.

8. Huynh TK, Ostergaard A, Egsmose C, Masden OR. Preferences of patients and health professionals for route and frequency of administration of biologic agents in the treatment of rheumatoid arthritis. Patient Prefer Adherence. 2014;8:93-99.

9. Waterbury MH, Serluco JT, Laskowski LA, et al. Medical Pharmacy \& Oncology Trend Report ${ }^{\mathrm{T}}$. 2011 Second Edition. Orlando, FL: icore Healthcare; 2011. Available from: http://icorehealthcare.com/ media/422047/trend_report_2011.pdf. Accessed March 15, 2014.

10. Vavricka SR, Bentele N, Scharl M, et al. Systematic assessment of factors influencing preferences of Crohn's disease patients in selecting an anti-tumor necrosis factor agent (CHOOSE TNF TRIAL). Inflamm Bowel Dis. 2012;18(8):1523-1530.

11. Hadaway L. Development of an infusion alliance. J Infus Nurs. 2010;33(5):278-290.

12. Foley JF, Dunne AM. Successful management of a neurology infusion practice. Int J MS Care. 2011;13(2):95-104.

13. Vizcarra C. Module 4. Nursing management of the infusion patient. In: American College of Rheumatology. Fundamentals of Rheumatology. Atlanta, GA; 2012. Available from www.rheumatology.org/apps/FRC/ Lectures. Accessed March 15, 2014.

14. Mayo Clinic Health Policy Center. A Foundation for Health Care Reform Legislation. Rochester, MI: Mayo Clinic. Available from: http:// www.mayoclinic.org/documents/viewpoint4-pdf/DOC-20079677. Accessed March 15, 2014. 


\title{
Supplementary materials
}

\author{
A Patient survey \\ Please identify your specialist and answer the following questions to help determine the best choice for your infusions.

$\begin{array}{ll}\text { Division/Dept: } & \text { Rheumatology Gastroenterology Nephrology Neurology Dermatology } \\ & \text { Transplant }\end{array}$

Answer using the following: 5= strongly agree $4=$ agree $3=$ neutral $2=$ disagree $\quad 1=$ strongly disagree

$0=$ no comment

I. I am content having my infusions in a cancer infusion room.

2. I am not bothered by the cancer-focused environment of the current infusion room.

3. I understand that even though I am treated in a cancer center infusion room, my disease is not considered like a form of cancer.

4. It will not bother me if I have to enter the Cancer Institute building for my future infusions.

5. Given the choice, I would have no preference for my infusions to be in a non-cancer infusion center.

6. I am not worried about my privacy in the current infusion room (given the number of curtained infusion bays).

7. The updated environment of the new infusion center (new furniture, décor, new building) will be important to me when I get my infusions.

8. Comments:

\section{B Physician providers' and nurses' survey}

Please answer the following survey about the non-oncology patients you care for in the infusion room.

Answer using the following: $\begin{aligned} & 5=\text { strongly agree } \quad 4=\text { agree } \quad 3=\text { neutral } \quad 2=\text { disagree } \quad 1=\text { strongly disagree } \\ & 0=\text { no comment }\end{aligned}$

\begin{tabular}{|c|c|c|c|c|c|c|c|}
\hline $\mathrm{I}$. & I believe my non-oncology patients are content to get their infusions in a cancer infusion room. & 5 & 4 & 3 & 2 & I & 0 \\
\hline 2. & $\begin{array}{l}\text { I do not think my non-oncology patients are bothered by the cancer-focused environment } \\
\text { of the current infusion room. }\end{array}$ & 5 & 4 & 3 & 2 & I & 0 \\
\hline 3. & $\begin{array}{l}\text { My patients understand that even though they are treated in a cancer center infusion room, } \\
\text { their disease is not considered like a form of cancer. }\end{array}$ & 5 & 4 & 3 & 2 & I & 0 \\
\hline 4. & $\begin{array}{l}\text { I do not think it will bother my non-oncology patients to enter the Cancer Institute building } \\
\text { for their future infusions }\end{array}$ & 5 & 4 & 3 & 2 & I & 0 \\
\hline 5. & $\begin{array}{l}\text { Given the choice, my non-oncology patients would have no preference for their infusions to be } \\
\text { in a non-cancer infusion center. }\end{array}$ & 5 & 4 & 3 & 2 & I & 0 \\
\hline 6. & $\begin{array}{l}\text { My patients are not worried about confidentiality in the current infusion room (given the number } \\
\text { of curtained infusion bays). }\end{array}$ & 5 & 4 & 3 & 2 & I & 0 \\
\hline 7. & $\begin{array}{l}\text { The updated environment of the new infusion center (new furniture, décor, new building) will } \\
\text { be important to my patients when they get infusions. }\end{array}$ & 5 & 4 & 3 & 2 & I & 0 \\
\hline 8. & Comments: & & & & & & \\
\hline
\end{tabular}

Patient Preference and Adherence

\section{Publish your work in this journal}

Patient Preference and Adherence is an international, peer-reviewed, open access journal that focusing on the growing importance of patient preference and adherence throughout the therapeutic continuum. Patient satisfaction, acceptability, quality of life, compliance, persistence and their role in developing new therapeutic modalities and compounds to optimize clinical outcomes for existing disease states are major areas of interest for the journal. This journal has been accepted for indexing on PubMed Central. The manuscript management system is completely online and includes a very quick and fair peer-review system, which is all easy to use. Visit http://www. dovepress.com/testimonials.php to read real quotes from published authors. 